\title{
Perancangan Sistem Informasi Jurnal Perkuliahan Sebagai Upaya Monitoring dan Evaluasi Proses Pembelajaran (Studi Kasus : Prodi Teknik Industri Fakultas Teknik Universitas Kadiri)
}

\author{
Imam Safi' $\mathbf{i}^{(1)}$ \\ ${ }^{(1)}$ Teknik Industri Universitas Kadiri \\ Email: imam@unik-kediri.ac.id ${ }^{(1)}$
}

\begin{abstract}
Abstrak
Dalam proses pembelajaran di Program Studi Teknik Industri Fakultas Teknik Universitas Kadiri, monitoring dilakukan dengan melihat hasil pengisian jurnal perkuliahan, yaitu salah satu bagian administrasi perkuliahan. Dokumen jurnal perkuliahan berisi mengenai materi yang disampaikan Dosen kepada mahasiswa pada setiap pertemuan kuliah yang bertujuan untuk informasi dan data proses perkuliahan berlangsung. penelitian ini bertujuan merancang sebuah sistem informasi monitoring dan evaluasi proses pembelajaran melalui jurnal perkuliahan di Prodi S-1 Teknik Industri Fakultas Teknik Universitas Kadiri yang dimana diharapkan mampu memberi solusi dalam kegiatan monitoring dan evaluasi pembelajaran yang transparan, akuntabel dan realtime. Penelitian diawali dengan menganalisis kebutuhan sistem, kemudian melakukan pemodelan dengan UML dengan membuat use case diagram, class diagram dan activity diagram. Perancangan sistem menggunakan bantuan aplikasi CMS Wordpress dan Google Form. Penelitian ini menghasilkan sebah rancang bangun sistem informasi monioring dan evaluasi proses pembelajaran pada Prodi Teknik Industri Fakultas Teknik Universitas Kadiri berupa layanan pengisian jurnal perkuliahan secara online dan data tersimpan aman di cloud. Sehingga kegiatan monitoring dan evaluasi bisa lebih efektif dan efisien.
\end{abstract}

Kata Kunci : Jurnal Perkuliahan, Proses Pembelajaran, Monitoring dan Evaluasi

\begin{abstract}
In the learning process at the Industrial Engineering Study Program, Faculty of Engineering, Kadiri University, monitoring is carried out by looking at the results of the lecture journal entry, which is one of the lecture administration sections. Lecture journal documents contain material delivered by the lecturer to students at each lecture meeting aimed at information and data on the lecturing process. This research aims to design an information system monitoring and evaluation of the learning process through lecture journals in the S-1 Department of Industrial Engineering, Faculty of Engineering, University of Kadiri which is expected to be able to provide solutions in monitoring and evaluation of learning activities that are transparent, accountable and real-time. The study begins by analyzing system requirements, then modeling with UML by making usecase diagrams, class diagrams and activity diagrams. The system design uses the help of CMS Wordpress and Google Form applications. This research resulted in a monioring information system design and learning process evaluation at the Industrial Engineering Study Program at the Kadiri University Faculty of Engineering in the form
\end{abstract}


of online lecture journal filling services and data stored safely in the cloud. So that monitoring and evaluation activities can be more effective and efficient.

\section{Keyword : Journal of Lectures, Learning Process, Monitoring and Evaluation}

\section{Pendahuluan}

Proses pembelajaran merupakan salah satu proses yang penting dalam pelaksanaan Tri Dharma Perguruan Tinggi yang dalam pelaksanaannya dilakukan oleh dosen. Dosen merupakan komponen yang penting dalam suatu sistem pendidikan di perguruan tinggi, dimana peran, tugas dan tanggung jawab dosen terutama dalam proses pembelajaran merupakan hal yang sangat penting dalam mewujudkan tujuan pendidikan nasional [1], [2]. Dalam melaksanakan kegiatan proses pembelajaran perlu pemantauan dan evaluasi agar apa yang dilaksanakan oleh dosen menjadi lebih terarah dan sesuai dengan standar yang telah ditetapkan diperguruan tinggi

Sesuai dengan Peraturan Menteri Riset dan Pendidikan Tinggi Nomor 44 tahun 2015 tentang Standar Nasional Pendidikan Tinggi Bab I Pasal 1 ayat 10 bahwa pembelajaran adalah proses interaksi mahasiswa dengan dosen dan sumber belajar pada suatu lingkungan belajar. Di dalam peraturan tersebut juga disebutkan bahwa proses pembelajaran yang efektif dilakukan 16 kali pertemuan. Dalam menjalankan peraturan tentunya perlu suatu monitoring dan evaluasi agar tujuan dapat dicapai [3], [4]. Kegiatan monitoring dan evaluasi internal merupakan salah satu bentuk pertanggung jawaban Perguruan Tinggi dalam menjamin bahwa keterlaksanaan kegiatan akademik dilaksanakan sesuai dengan aturan dan mencapai sasaran yang telah ditargetkan. Melalui kegiatan monitoring ini juga, persoalan dan kendala yang dihadapi dalam implementasi dapat diantisipasi dan ditanggulangi.

Lembaga yang memonitoring dan mengevaluasi adalah Penjaminan Mutu [5], [6]. Menurut Rinda Penjaminan mutu pendidikan tinggi di perguruan tinggi adalah proses penerapan dan pemenuhan standar mutu pengelolaan dan pendidikan tinggi secara konsisten dan berkelanjutan, sehingga stakeholder (mahasiswa, orang tua, dunia kerja, pemerintah, dosen, tenaga penunjang,serta pihak lain yang berkepentingan) memperoleh kepuasan [7]. Dengan demikian, penjaminan mutu diharapkan dilakukan di seluruh perguruan tinggi dengan memperhatikan butir-butir mutu yang ditetapkan antara lain: kurikulum program studi, sumber daya manusia (dosen dan tenaga penunjang), mahasiswa, proses pembelajaran, prasarana dan sarana, suasana akademik, keuangan, penelitian dan publikasi, pengabdian kepada masyarakat, tata pamong.

Program Studi Teknik Industri Fakultas Teknik Universitas Kadiri adalah penyelenggara akademik di tingkat program studi yang berkewajiban melaporkan hasil pembelajaran kepada pimpinan. Proses monitoring dan evaluasi dilakukan oleh Unit Penjaminan Mutu Program Studi pada proses pembelajaran pada setiap semester yang bertujuan untuk memantau penerapan standar proses pembelajaran yang telah ditetapkan.

Monitoring merupakan kegiatan pemantauan yang dilakukan untuk mengetahui kegiatan proses pembelajaran yang dilakukan oleh dosen [8]. Sedangkan evaluasi merupakan hasil akhir dari hasil monitoring yang dilakukan selama proses belajar mengajar yang dilakukan selama satu semester. Dalam proses pembelajaran, monitoring dilakukan dengan melihat hasil pengisian jurnal perkuliahan, yaitu salah satu bagian administrasi perkuliahan. Dokumen jurnal perkuliahan berisi mengenai materi yang disampaikan Dosen kepada mahasiswa pada setiap pertemuan kuliah yang bertujuan untuk informasi dan data proses perkuliahan berlangsung. Selain itu juga untuk mengontrol pelaksanaan dalam proses pembelajaran. Pelaksanaan jurnal perkuliahan masih dilakukan secara manual dengan menulis di lembar kertas, informasi dan data yang diperoleh tidak tepat waktu dan tidak terlalu akurat. Oleh sebab itu diperlukan langkah inovasi dalam menyelesaikan masalah tersebut dengan menghubungkan dengan sistem informasi yang diharapkan mampu memberikan solusi efektif dan efisiensi, seperti data yang tepat waktu, paperless, dan mampu memberikan informasi yang akurat untuk pengambilan keputusan [9], [10].

Sistem informasi dapat didefenisikan secara teknis sebagai satuan komponen yang saling berhubungan yang mengumpulkan (atau mendapatkan kembali), memproses, menyimpan, dan mendistribusikan informasi untuk mendukung pengambilan keputusan dan kendali dalam suatu 
organisasi. Sistem informasi merupakan sistem yang mengumpulkan, memproses, menyimpan, menganalisis, dan menyebarkan informasi untuk tujuan tertentu .

Dengan menganalisis kebutuhan sistem perkuliahan, maka akan terlihat suatu prosedur (SOP) yang ada kemudian mengakitakan dengan sistem Plan, Do, Check, Action (PDCA) [11]. Berdasarkan hal tersebut maka penelitian ini bertujuanmerancang sebuah sistem informasi monitoring dan evaluasi proses pembelajaran melalui jurnal perkuliahandi Prodi S-1 Teknik Industri Fakultas Teknik Universitas Kadiri yang dimana diharapkan mampu memberi solusi dalam kegiatan monitoring dan evaluasi pembelajaranyang transparan, akuntabel dan realtime.

\section{Metode Penelitian}

Penelitian ini dimulai dengan melakukan studi literatur sebagai dasar dalam penelitian, kemudian melakukan observasi dilapangan guna mengetahui kondisi dari obyek yang akan diteliti dengan menganalisis sistem pelaksanaan jurnal perkuliahan di Program Studi Teknik Industri Fakultas Teknik Universitas Kadiri sehingga diketahui permasalahan yang akan dibahas dan dijadikan tujuan dalam penelitian ini. Batasan masalah serta asumsi ditentukan agar penelitian ini tidak keluar dari tujuan penelitian yang telah ditetapkan.

Setelah tahapan diatas dilakukan selanjutnya adalah dengan menguraikan kebutuhan sistem. Kebutuhan sistem menggambarkan proses atau fungsi yang harus dikerjakan oleh sistem dalam melayani kebutuhan pengguna (user). Maka dari itu fungsi utama yang harus ada dalam sistem informasi jurnal perkualiahan adalah [12] :

a. Fungsi Login

Fungsi ini digunakan oleh mahasiswa penanggung jawab mata kuliah (PJMK) di Program Studi Teknik Industri Fakultas Teknik Universitas Kadiri untuk masuk dan memubka lembar jurnal perkuliahan secara online.

b. Fungsi Mengisi Lembar Jurnal Perkuliahan

Fungsi ini digunakan oleh PJMK untuk mengisi hasil pembelajaran di kelas yang dilakukan pada setiap pertemuan perkuliahan, melingkupi data PJMK, pilihan pertemuan kuliah, tanggal dan hari kuliah, jam kuliah, Dosen pengampu di kelas, pokok bahasan pada setiap pertemuan, deskripsi materi kuliah, dan refleksi hasil kuliah.

c. Fungsi Menyimpan Dokumen Pengisian Jurnal Perkuliahan

Fungsi ini digunakan untuk menyimpan hasil pengisian jurnal perkuliahan yang berbentuk file pdf. Yang nantinya akan di upload di website.

d. Fungsi Menginput dan Mengecek Daftar Penanggung Jawab Mata Kuliah (PJMK).

Fungsi ini untuk menginput data PJMK dan menampilkan di website sehingga semua pengguna bisa melihat daftar PJMK yang sudah dibagi.

e. Fungsi Mengecek Isian Jurnal Perkuliahan.

Fungsi ini digunakan untuk mengecek dokumen hasil isian jurnal perkuliahan setiap mata kuliah pada tiap pertemuan.

f. Fungsi Menginput dan Mengecek Jumlah Pertemuan Perkuliahan.

Fungsi ini digunakan untuk menginputkan dokumen ke website sehingga semua pengguna bisa melihat hasil isian jurnal perkuliahan.

g. Fungsi Menginput dan Mengecek Daftar Hadir dan Evaluasi Penilaian Mahasiswa.

Fungsi ini digunakan untuk menginputkan data hasil absensi mahasisawa serta penilaian dosen terhadap mahasiswa pada setiap pertemuan perkuliahan.

Tahap selanjutnya adalah menggunakan pendekatan dengan model sistem, model sistem bertujuan untuk menggambarkan kebutuhan sistem secara jelas dan lengkap [13]. Model sistem yang digunakan adalah berorientasi objek yaitu metode untuk menganalisa dan merancang sistem dengan pendekatan berorientasi object [14]. Object diartikan sebagai suatu entitas yang memiliki identitas, state, dan behavior. Permodelan sistem informasi jurnal perkuliahan ini menggunakan pendekatan berorientasi objek yaitu menggambarkan usecase diagram, clas diagram dan activity diagram [15], [10] . Berikut gambaran dari model tersebut : 
a. Use case Diagram

Use case diagram menunjukkan bagaimana aktor (pengguna) berinteraksi dengan sistem dan bagaimana modul sebuah sistem dijalankan [16], [17].

b. Class Diagram

Class diagram menggambarkan struktur dan deskripsi class, package, dan objek beserta hubungan satu sama lain.

c. Activity diagram

Digunakan untuk menggambarkan alur aktivitas/kegiatan dari proses bisnis, juga untuk memodelkan respon yang akan terjadi apabila suatu operasi dalam sistem dijalankan.

Tahap terakhir adalah implementasi sistem dengan menggunakan beberapa software yang menunjang pembuatan sistem informasi jurnal perkuliahan yaitu :

\section{Content Management System (CMS) dari Wordpress}

Adalah suatu sistem yang digunakan untuk mengelola dan memfasilitasi proses pembuatan, pembaharuan, dan publikasi konten secara bersama (collaborative content management) [14]. Kegunaan Kegunaan CMS adalah untuk mempermudah user membangun sebuah situs website dan juga memudahkan dalam mengedit konten ataupun template tanpa harus mempelajari begitu dalam beberapa bahasa pemograman website yang membutuhkan waktu yang sangat lama, seperti HTML, PHP, MySQL dan lain-lain.

Wordpress adalah sebuah aplikasi sumber terbuka (open source) yang sangat populer digunakan sebagai mesin blog (blog engine). Wordpress dibangun dengan bahasa pemrograman PHP dan basis data (database) MySQL. PHP dan MySQL, keduanya merupakan perangkat lunak sumber terbuka (open source software). Selain sebagai blog, Wordpress juga mulai digunakan sebagai sebuah CMS (Content Management System) karena kemampuannya untuk dimodifikasi dan disesuaikan dengan kebutuhan penggunanya.

2. Google Form

Adalah salah satu aplikasi dari akun Google yang bersifat umum dan dapat diakses secara gratis jika memiliki akun Google serta dapat dihubungkan ke spreadsheet [18]. Dengan Google Forms, pengguna dapat membuat suatu form yang dapat ditemukan oleh semua orang di penjuru dunia. Untuk mengisi Form yang telah dibuat pada Google Form, responden tidak perlu memiliki akun Google sehingga dapat dikatakan Form tersebut bersifat umum [19]. Pembuatan Google Form dapat dilakukan melalui laptop, komputer, dan bahkan smartphone. Dengan Google Forms kita dapat membuat dan mengirim survei melalui email. Google Forms hanya memiliki satu versi layanan, yaitu layanan gratis dengan pengajuan pertanyaan dan responden yang tidak terbatas. Google Form adalah alat yang berguna untuk membantu merencanakan acara, mengirim survei, memberikan siswa kuis, atau mengumpulkan informasi yang mudah dengan cara efisien.

\section{Hasil dan Pembahasan}

Sistem informasi jurnal perkuliahan berbasis website ini dirancang dengan menggunakan model berorientasi obyek dengan desain sistem yang digambarkan melalui UML dengan tahapan awal :

1. Use case diagram

Berdasasarkan kebutuhan jurnal perkuliahan maka dapat digambarkan diagram use case pada sistem informasi monitoring dan evaluasi proses perkuliahan sebagai berikut : 


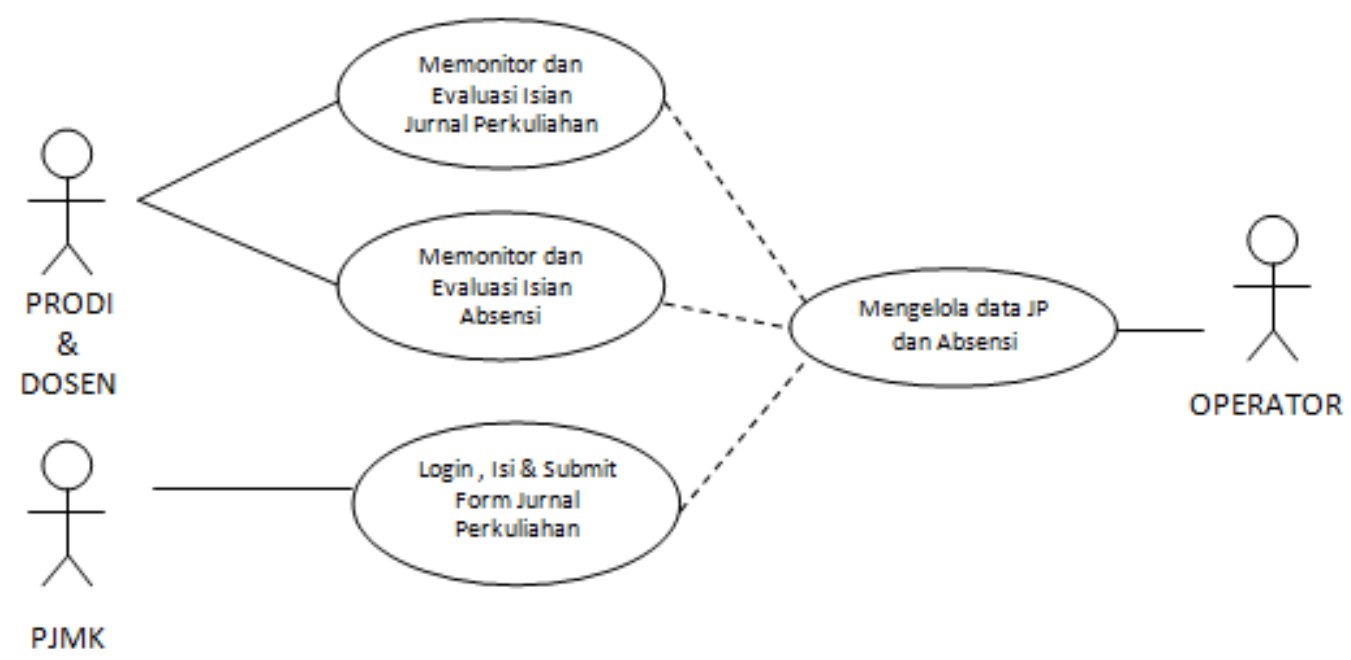

Gambar 1. Use case Diagram Sistem Informasi Jurnal Perkuliahan

a. Penanggungjawab Mata Kuliah (PJMK) bertugas mengisi form jurnal perkuliahan secara online pada alamat website prodi dengan login terlebihdahulu menggunakan password default kemudian isian jurnal perkuliahan dilakukan setelah selesai melaksanakan perkuliahan.

b. Operator dapat mengelola semua data baik data hasil jurnal perkuliahan dan data absensi utnuk dimasukkan ke kolom setiap mata kuliah pada setiap pertemuan, begitu juga dengan data absesnsi.

c. Prodi maupun Dosen dapat melihat hasil dari isian jurnal perkuliahan oleh PJMK kemudian dapat dilakukan evaluasi.

2. Class Diagram

Class diagram pada sistem informasi jurnal perkuliahan ini bertujuan untuk mengetahui hubungan struktur komponen satu dengan yang lain, adapun gambar seperti dibawah ini. 


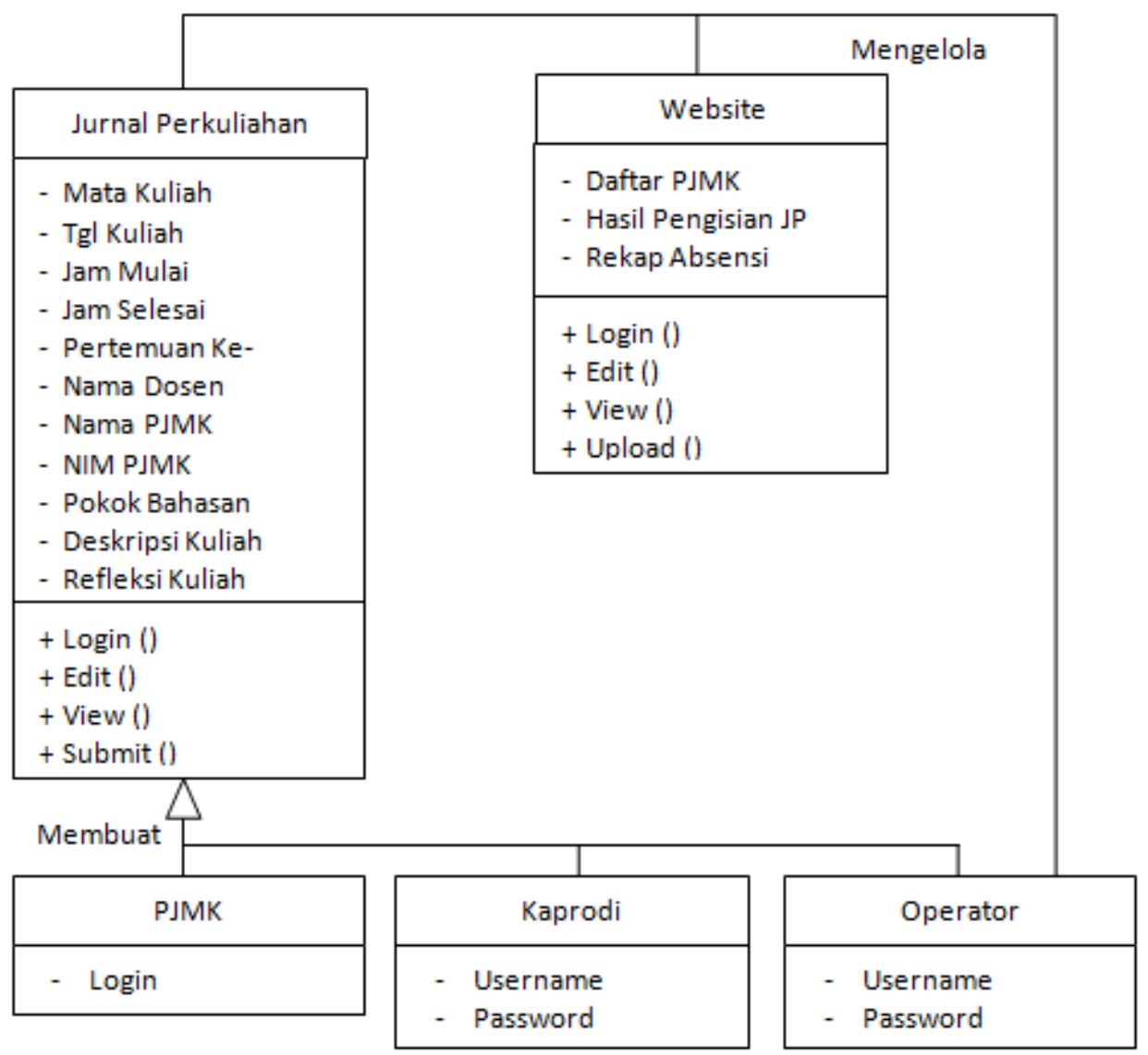

Gambar 2. Diagram Class

3. Activity diagram

Untuk menggambarkan alur dalam sistem informasi jurnal perkualiahan saat dijalankan, maka perlu digambarkan activity diagram seperti pada gambar dibawah ini.

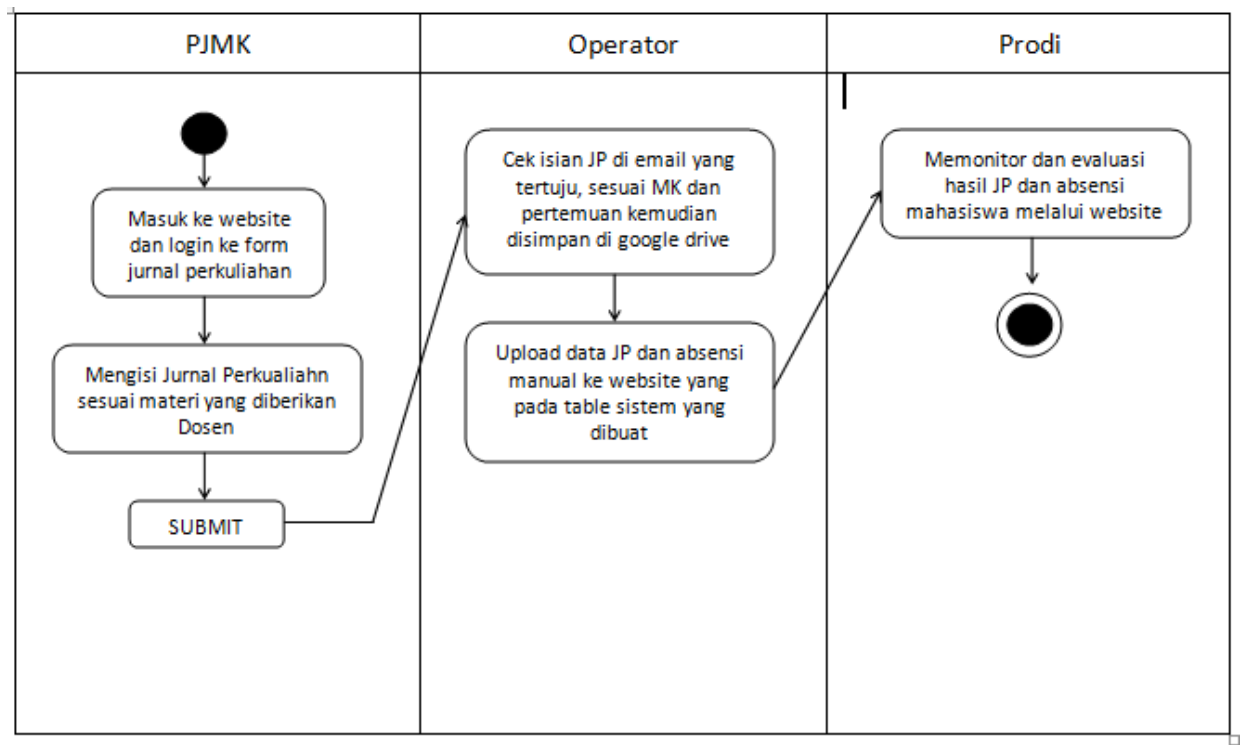

Gambar 3. Activity diagram 
Setelah melakukan permodelan sistem informasi maka tahap selanjutnya adalah implementasi sistem dari jurnal perkulian sebagai berikut :

1. Tampilan form jurnal perkuliahan

Merupakan tampilan dari form jurnal perkuliahan yang akan di isi oleh PJMK setiap selesai melakukan pertemuan perkualiahan. Form dibuat dengan menggunakan aplikasi dari Google Form kemudian semua unsur yang ada pada class diagram dimasukkan. Jika sudah mengisi , PJMK menulis alamat email yang sudah di tetapkan agar data isian masuk dan terkumpul di satu tempat. Tampilan form dapat dilihat pada gambar 4 berikut :

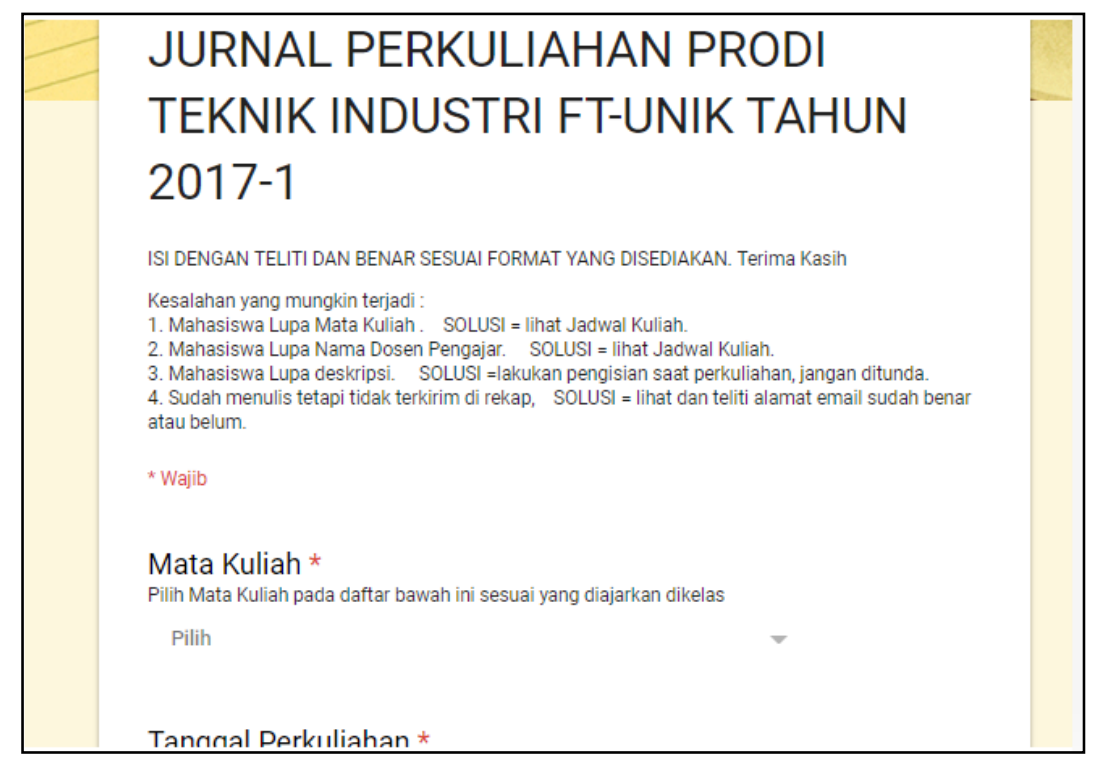

Gambar 4. Form Jurnal Perkuliahan.

2. Tampilan data isian jurnal perkuliahan.

Data isian jurnal perkuliahan terkumpul akun email penjaminan mutu program studi. Yang kemudian disimpan dalam bentuk file pdf. Ke google drive akun tersebut. Setiap data dicek pertemuan perkuliahannya, nama mata kuliah dan lain-lain sudah sesuai atau belum, jika sudah maka di pilah untuk dimasukkan ke setiap folder dalam google drive. Adapun tampilan data kumpulan isian jurnal perkuliahan sebagai berikut :

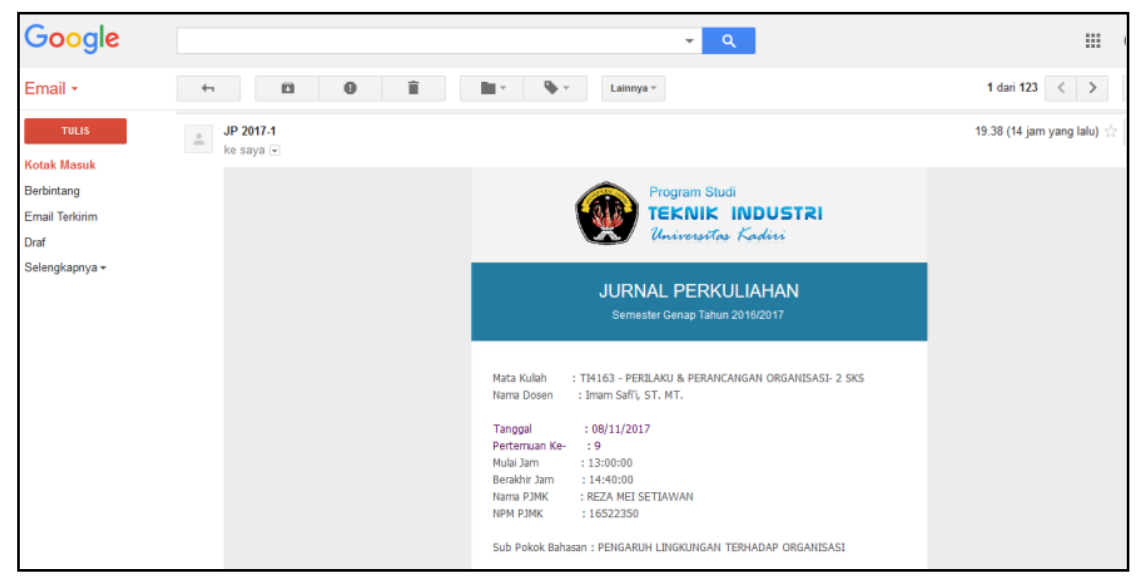




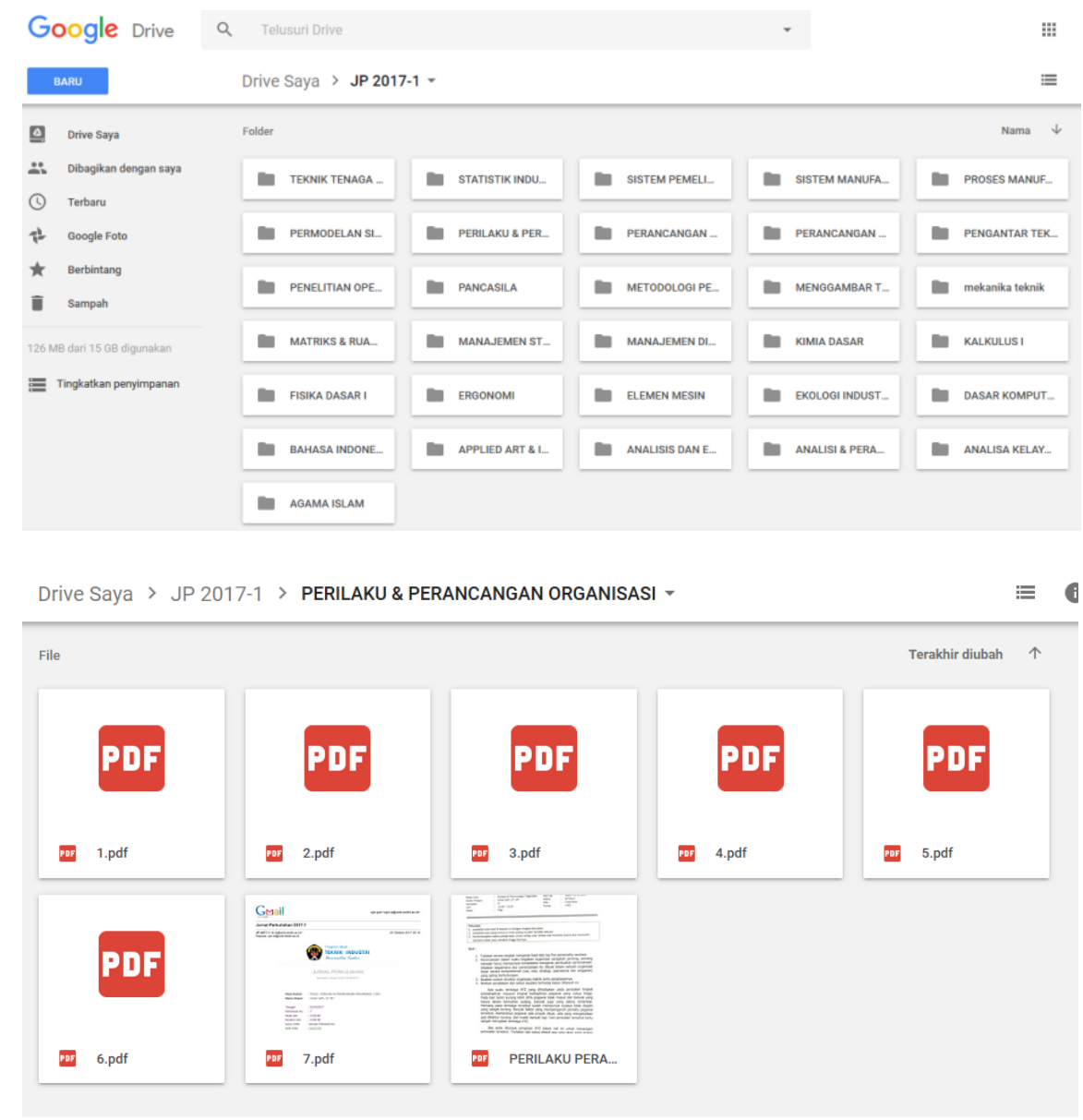

Gambar 5. Tampilan data isian jurnal perkuliahan

3. Tampilan upload data jurnal perkuliahan di website prodi

Data yang tersimpan di google drive yang sudah dikelola operator prodi, selanjutnya dilakukan proses upload ke website prodi agar terintegrasi saat pengguna ingin melihat isian jurnal perkuliahan. Plugin Tablepress digunakan untuk mengupload link dari data jurnal perkualiahan yang sudah tersimpan di google drive. Adapun tampilan seperti pada gambar dibawah ini.

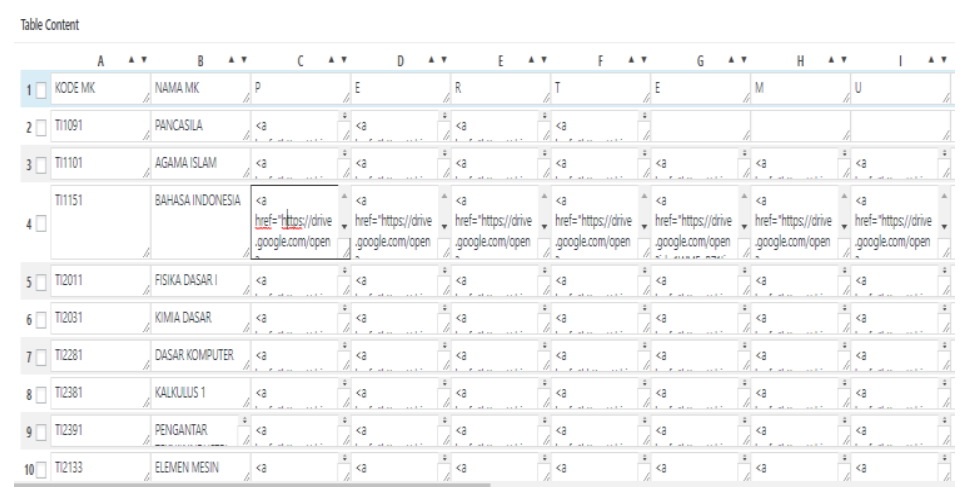

Gambar 6. Tampilan upload data jurnal perkuliahan di website. 
4. Tampilan monitor isian jurnal perkualiahan dan absensi.

Setelah semua data di upload oleh operator prodi maka semua pihak yang berkepentingan bisa melihat hasil dari isian jurnal perkuliahan dengan menuju alamat website prodi Teknik Industri Fakultas Teknik Universitas Kadiri pada menu pendidikan kemudian jurnal perkualiahan.

Dihalaman tersebut akan tersaji sheet pilihan untuk melihat daftar PJMK, Isian jurnal perkuliahan dan riwayati absensi dan penilaian seperti tampak pada gambar 7 dibawah ini.

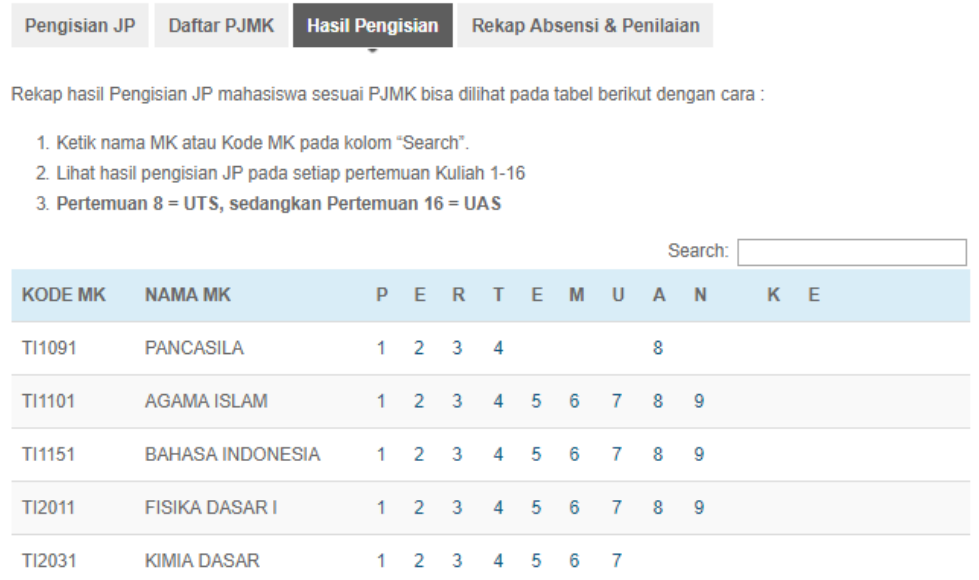

Gambar 7. Tampilan monitor isian jurnal perkuliahan

\section{Kesimpulan}

Berdasarkan hasil dan pembahasan pada penelitian ini, maka dapat ditark kesimpulan sebagai berikut :

1. Kegiatan monitoring dan evaluasi dalam proses pembelajaran di Prodi Teknik Industri Fakultas Teknik Universitas Kadiri melalui salah satunya kegiatan pengisian jurnal perkuliahan bisa lebih efektif dan efisien karena dilakukan dengan dukungan teknnologi informasi, data yang didapat menjadi cepat tersaji serta tidak banyak menggunakan kertas (paperless).

2. Penelitian ini menghasilkan sebah rancang bangun sistem informasi monioring dan evaluasi proses pembelajaran pada Prodi Teknik Industri Fakultas Teknik Universitas Kadiri berupa layanan pengisian jurnal perkuliahan secara online dan data tersimpan aman di cloud.

3. Sistem ini dapat membantu Prodi dan Penjaminan Mutu untuk terus mengevaluasi proses pembelajaran di Prodi Teknik Industri Fakultas Teknik Universitas Kadiri.

Adapun saran dalam penelitian ini untuk bisa disempurnakan lebih lanjut adalah sebagai berikut :

1. Sistem absensi mahasiswa saat proses belajar mengajar masih dilakukan secara manual sehingga masih banyak menggunakan kertas sebagai media pencatatan absensi, kedepan perlu dikembangkan lagi rancangan siste absensi onlien dan terintegrasi dengan jurnal perkuliahan.

2. Sistem bisa lebih dikembangkan ke pemrograman java agar lebih sempurna lagi.

\section{Daftar Pustaka}

[1] K. Y. Saputra, "Pengaruh Proses Pembelajaran Dan Motivasi Belajar Terhadap Hasil Belajar Ips Siswa Smp Maulana Pegayaman," J. Pendidik. Ekon. Undiksa, vol. 5, no. 1, 2015.

[2] A. Kirom, "Peran Guru Dan Peserta Didik Dalam Proses Pembelajaran Berbasis Multikultural," Al Murabbi, vol. 3, no. 1, pp. 69-80, 2017.

[3] I. Mutia, "Kajian Penerapan E-Learning Dalam Proses," Fakt. Exacta, vol. 6, no. 4, pp. 278$289,2013$.

[4] N. ; Sriwihajriyah, E. L. ; Ruskan, and A. Ibrahim, "Sistem pembelajaran dengan e-learning untuk persiapan ujian nasional pada SMA Pusri Palembang," J. Sist. Inf., vol. 4, no. 1, pp. 450- 
449, 2012.

[5] Nanang Fattah, "Sistem Penjaminan Mutu Pendidikan," Bandung: Remaja Rosda Karya, vol. XI, no. 9, pp. 1689-1699, 2018.

[6] A. Sulaiman, J. Wibowo, Udik Budi Akuntabilitas, and M. Pendidikan, "Implementasi Sistem Penjaminan Mutu Internal Sebagai Upaya Meningkatkan Mutu Pendidikan Di Universitas Gadjah Mada the Implementation of Internal Quality Assurance System As an Effort To Improve Quality of Education At Gadjah Mada University," J. Akuntabilitas Manaj. Pendidik., vol. 4, no. 1, pp. 17-32, 2016.

[7] R. Hidayat, "Sistem Informasi Ekspedisi Barang Dengan Metode E-CRM Untuk Meningkatkan Pelayanan Pelanggan," Sisfotek Global. 2014.

[8] T. L. Wiemken, S. P. Furmanek, W. A. Mattingly, J. Haas, J. A. Ramirez, and R. M. Carrico, "Googling your hand hygiene data: Using Google Forms, Google Sheets, and R to collect and automate analysis of hand hygiene compliance monitoring," Am. J. Infect. Control, vol. 46, no. 6, pp. 617-619, Jun. 2018.

[9] T. Herawati, "Pengaruh Sistem Pengendalian Intern Terhadap Kualitas Laporan Keuangan (Survei Pada Organisasi Perangkat Daerah Pemda Cianjur)," STAR - Study Account. Res., 2014.

[10] P. Kesehatan, K. Jakarta, A. Ramdhani, and C. Kintan, "Sistem Informasi Akademik Sistem Informasi Akademik," no. 021, pp. 1-2, 2018.

[11] E. A. P. H. Putra and Z. F. Ikatrianasari, "Penerapan Lean Manufacturing melalui Metode Gemba Kaizen dengan Pendekatan Siklus PDCA untuk Peningkatan Produktivitas di PT. XYZ, Bekasi," Magister Tek. Ind., vol. ISBN : 978, pp. 978-979, 2012.

[12] A. Wicaksono, "PERANCANGAN SISTEM AKUNTANSI PENJUALAN TUNAI TERKOMPUTERISASI PADA AL ISHBA KARPET," Nominal, Barom. Ris. Akunt. dan Manaj., 2012.

[13] R. J. Ang, "Use of content management systems to address nursing workflow," Int. J. Nurs. Sci., vol. 6, no. 4, pp. 454-459, 2019.

[14] S. Wan, D. Li, and J. Gao, "Exploring the Advantages of Content Management Systems for Managing Engineering Knowledge in Product-service Systems," Procedia CIRP, vol. 56, pp. 446-450, 2016.

[15] M. Susanti, "Perancangan Sistem Informasi Akademik Berbasis Web pada SMK Pasar Minggu Jakarta," vol. III, No. 1, pp. 100-200, 2018.

[16] S. Sabharwal, P. Kaur, and R. Sibal, "Empirical and Theoretical Validation of a Use case Diagram Complexity Metric," Int. J. Inf. Technol. Comput. Sci., vol. 9, no. 11, pp. 35-47, 2017.

[17] R. Klimek and P. Szwed, "Formal Analysis Of Use case Diagrams," Comput. Sci., vol. 11, no. 1, pp. 115-115, 2010.

[18] Gsuite, “Google Form (G Suite by Google Cloud),” gsuite.google.com, 2019. [Online]. Available: https://gsuite.google.com/intl/en_id/products/forms/?utm_source=google\&utm_medium=cpc\&ut m_campaign=japac-ID-all-en-dr-bkws-all-golden-trial-e-dr-1007173\&utm_content=text-adnone-none-DEV_c-CRE_354992628879-ADGP_Hybrid \%257C AW SEM \%257C BKWS EXA \%257C Forms \%25. [Accessed: 21-Jul-2019].

[19] H. husein Batubara, "Penggunaan Google Form sebagai Alat Penilaian Kinerja Dosen di prodi PGMI UNISKA Muhammad Arsyad Al-Banjari," Univ. Islam kalimantan, vol. 8 Nomor 1, no. Google Form sebagai media penilaian kinerja dosen dan respon mahasiswa terhadap penggunaannya, 2016. 